\title{
Introduction to Entrepreneurship and Knowledge Management Minitrack
}

\author{
Katia Passerini \\ St. John's University \\ passerik@stjohns.edu
}

\author{
Michael R. Bartolacci \\ Penn State University - Berks \\ mrb24@psu.edu
}

Entrepreneurship is often synonymous with invention, flexibility, adaptability and innovation "on the fly." The dynamic nature of start-ups makes it difficult for innovators to focus on knowledge management throughout the entrepreneurship cycle (innovation, triggering event, implementation and growth). The innovation stage calls for agility and, in highly technical and competitive industries, "secrecy." The intermediate stages (triggering and implementation) are often characterized by business plans, presentations to investors, networking, and are less suited for knowledge capture and codification. The growth period requires a focus on processes and systems and the codification of explicit knowledge rather than transfer of tacit knowledge. As a result of this dynamic nature of a firm's activities, knowledge management is often an afterthought for entrepreneurs rather than a driver of firm performance and long term sustainability. This track reviews the relationship between knowledge management and entrepreneurial activities and summarizes key open questions.

The research in this mini-track vary greatly in their interpretations of the intersection of knowledge management and entrepreneurship.

Barbara Durkin, Izabella Lokshina, and Cees J.M. Lanting in "Data Analysis Services Related to the IoT and Big Data: Potential Business Opportunities for Third Parties," examine business models related to the exploitation of data generated by the "Internet of Things" (IoT). In particular they tackle the problem of how knowledge management can be utilized to drive decision making despite the huge volume of data that is generated in this context and the potential to misinterpret collected data. They identify several industry examples where IoT data can be used to increase customer service, product quality, and ultimately, profitability for the firm.

To this end, an important point they discuss is that "Big Data' in and of itself is not useful unless there are opportunities to apply the insights gleaned from it. Only business models that support the flexibility to change business processes based on these insights will use it successfully. They stress that companies need to have what is enveloped in the notion of entrepreneur, namely agility, in order to compete in today's ever-changing global market. This agility includes the ability to change based on process data that was collected through the IoT.

Cesar Bandera and Ellen Thomas take a different view of knowledge management and entrepreneurship in their work entitled "Collaboration and Critical Mass among Nascent Companies." This work examines the link between social capital and the success of nascent companies. In particular it breaks apart the notion that as new companies tend to form in clusters, they are inherently able to take advantage of the social capital formed through clustering and interrelationships. Their work explores the notion of a "critical mass" that is required for the social capital to be utilized properly for such companies. They also bring to light the difference between "knowledge stock" and "knowledge flow"; an important distinction when examining how entrepreneurial companies can leverage knowledge gained by other fledgling organizations.

Celina Olszak, Tomasz Bartuś, and Paweł Lorek present a framework for knowledge management that would be well suited for entrepreneurial enterprises in "An Information System Design for Organizational Creativity Support.” In particular, their framework looks at creativity support which is a key component of the overall KM process. Their systems framework proposes that creativity in an organization is fostered through the utilization of four agents: searching agents, monitoring agents, capturing agents, and discovering and suggesting agents. Their systems framework encompasses six steps that utilizes the nature of each agent to forward the overall KM process with respect to organizational creativity.

The minitrack co-chairs want to thank authors and reviewers for their work in making this second year of the minitrack a success and we look forward to building this research community in the coming years. 